\title{
Geochemical Modeling Applied in Waste Disposal, and Its Relevance for Municipal Solid Waste Management
}

\author{
Francisco Araujo ${ }^{1}$, Hugo Fantucci ${ }^{1}$ (D), Everton Nunes ${ }^{2}(\mathbb{D})$ and Rafael M. Santos ${ }^{1, *(\mathbb{D})}$ \\ 1 School of Engineering, University of Guelph, Guelph, ON N1G 2W1, Canada; faraujo@uoguelph.ca (F.A.); \\ hfantucc@uoguelph.ca (H.F.) \\ 2 Federal Institute of Education, Science and Technology of Ceará (IFCE), Caucaia, CE 62670-000, Brazil; \\ everton.nunes@ifce.edu.br \\ * Correspondence: santosr@uoguelph.ca
}

Received: 4 September 2020; Accepted: 23 September 2020; Published: 25 September 2020

\begin{abstract}
Solid waste management is a challenge for municipalities mainly due to the increasing generation of residues worldwide. Much waste still ends up in landfills, either as a final disposal sink, or as a temporary yet long-term storage prior to eventual landfill mining. Through degradation and infiltration processes, these materials threaten groundwater, soil and the environment, invariably causing expressive societal concern. Waste managers, environmentalists and regulators alike focus upon predicting how these complex geochemical systems will evolve over decades. Geochemical modeling and transport simulation are commonly used to support the design, operation or characterization of these dynamic systems. In this targeted critical review of the literature over the last two decades concerning geochemical modeling applications to waste disposal (including municipal, incineration residue, and industrial), we have attempted to provide an assessment of the current state of knowledge in this field, supported by a comprehensive list of modeling methodologies and data analyses, relevant for municipal solid waste (MSW) management systems. The information provided is meant to be useful for specialists when planning, implementing or adapting MSW systems.
\end{abstract}

Keywords: municipal solid waste; landfill; geochemical modeling; leaching

\section{Introduction}

One third of the total waste generated worldwide is disposed of utilizing environmentally unsafe methods, e.g., landfill disposal, dumping at sea, and underground disposal. The World Bank (2016) predicts a rate of increase of approximately $70 \%$ by 2050 , an expected 3.40 billion tonnes annually of municipal solid waste (MSW), challenging cities to create more environmentally sustainable methods of managing this increasingly complex problem. According to the World Bank, the global disposal and treatment of MSW is presently distributed between open dumps (33\%) and different types of landfills (36.6\%) (unspecified, controlled and sanitary), followed by recycling $(13.5 \%)$, incineration $(11.1 \%)$, composting (5.5\%), and other methods (0.3\%) [1].

In terms of their composition, MSW is extremely diverse, depending on many variables and sources, thus making it difficult to predict possible contaminants in these complex materials, which is exacerbated by different standards of characterization between countries. For this reason, waste managers are required to take short-, medium-, and long-term planning decisions, while considering the articulated multi-echelon supply chain of waste generation, treatment and disposal. In all such situations, neglecting the uncertainty of the waste generation rates can lead to unreliable decision plans. Appropriate storage of waste has been one of the main concerns in risk assessments of the industry, especially in developing countries where this practice is quite common. 
As a result of the rapid population increase, a great quantity of waste disposal to the land surface is seen as problematic. After being exposed to degradation and infiltration for a long duration, the waste products threaten the groundwater, soil, and environment; thus, there is increasing awareness among the society about the environmental problems [2] The impact of leachate on groundwater and on other water resources has attracted attention because of its devastating environmental significance. Leachate migration from landfills poses a high risk to groundwater resources if not satisfactorily managed [3-6].

There are several treatment options for MSW; thus, choosing the "optimal" or the best available option(s) usually involves decisions on the technology, location, and capacity of the treatment plant [7]. These decisions are often made by considering various criteria, such as: environmental impacts (e.g., global warming, human health risks, resource depletion, ecosystem damage); associated economic costs and benefits; and regional characteristics (e.g., waste generation rate, and political and social factors). Some of the most applied MSW treatment strategies include landfilling and waste-to-energy technology [8].

The geochemical computer model is an important innovation that exponentially evolved in the last decades, and that now plays a vital role in several areas of study, ranging from developing new models for surface complexation, reactive transport models, or the generation of thermodynamic data used to simulate or predict solubility reactions. An important application of geochemical modeling involves supporting the explanation or characterization of engineering systems related to waste management, wastewater reuse, evaluation of water quality from a landfill, metal speciation within soils in industrial areas, new technologies or process for waste treatment, and even the evaluation of the potential to use solid wastes in carbon sequestering processes. The goal of this study is review analytically and critically recent scientific literature employing geochemical modeling in order to identify approaches, trends and limitations of such modeling applied in waste disposal, with relevance for MSW management.

\section{Theoretical Framework}

\subsection{Landfills and Municipal Solid Waste Incineration}

Landfills, the primary MSW disposal method worldwide, are usually not regulated in developing countries (e.g., open dumps). Non-regulated landfills are also the source of significant greenhouse gas emissions (GHG) and volatile organic compounds (VOCs) in the atmosphere [9]. The regulated landfills are constructed in selected sites with multiple layers of clay and geomembrane to prevent the transport of leachate in the groundwater direction. A representative illustration of the traditional configuration of the regulated and non-regulated landfills (adapted from Abdel-Shafy and Mansour [10]) is presented in Figure 1.

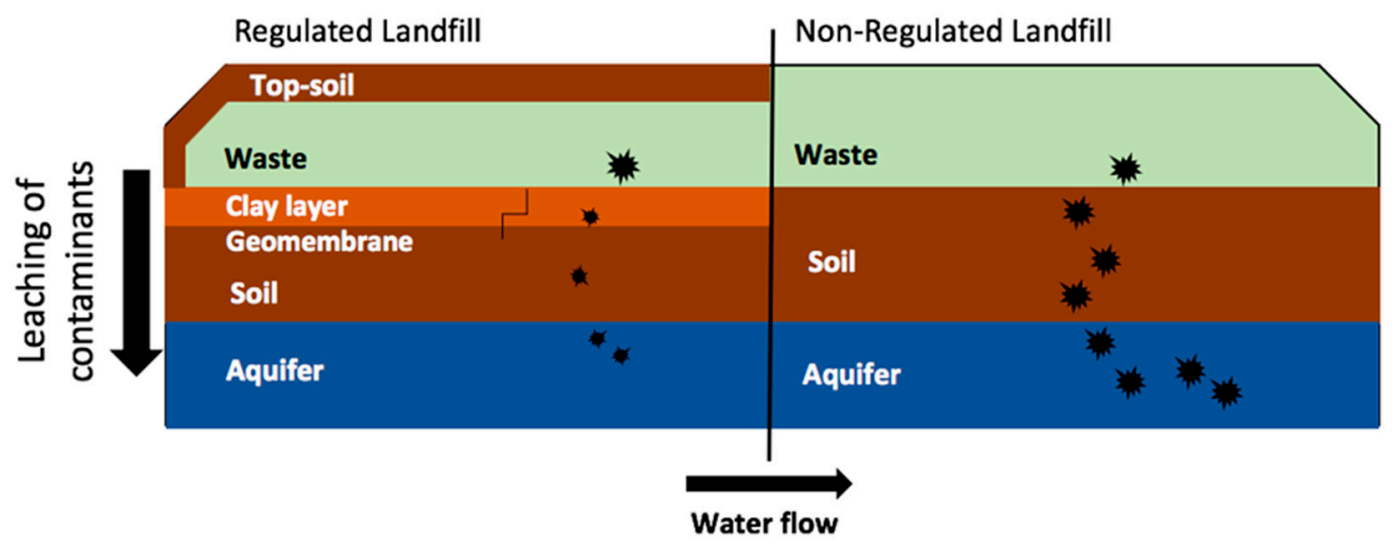

Figure 1. Simplified regulated and non-regulated landfill representative sample with contaminants (black dots) leaching process. Adapted from Shafy and Mansour [10]. 
Municipal solid waste incineration (MSWI) is becoming the most applied method of MSW management in industrialized countries $(62 \%)$, regarded as a practical alternative to minimize the 'volume, mass and harmfulness' of MSW that has historically been disposed of in landfills [11]. Although incineration is an effective way to reduce MSW and produce heat, which is recovered and normally converted to electrical energy, most of the by-products (bottom and fly ashes) still end up in landfills because of non-conformity to environmental regulations, thereby possibly generating additional pollutants. One of the principal concerns regarding future utilization of the residues from MSW incineration is possible contamination of the environment due to the release of elements when in contact with water; i.e., leaching. Thus, quantification of leaching of particular elements prior to utilization and/or landfilling of MSWI residues is required. Yet, a portion of such by-products can be recycled and utilized in building materials. In fact, certain quantities are exported from producing countries due to higher allowable leaching levels (principally of $\mathrm{Cu}, \mathrm{Zn}$ and $\mathrm{Pb}$ ) in neighboring countries; for example, the acceptable content of $\mathrm{Cu}$ is $25 \mathrm{mg} / \mathrm{m}^{2}$ in Belgium and $98 \mathrm{mg} / \mathrm{m}^{2}$ in the Netherlands for shaped materials (based on NEN 7345 diffusion test), creating an opportunity for utilization in countries with less rigorous regulations [12].

Several geochemical modeling studies have been made around solid waste sites, often undertaken in a landfill, in open dumps, and in the surrounding environment. Most studies related to leaching behavior are concerned with improving the understanding of long-term environmental risk assessment, while focusing on predicting the leaching and reactive transport time of known components of solid wastes [13].

\subsection{Contamination Processes and the Role of Leaching}

In this work, a thin slice was taken from the extensive field of knowledge covered by geochemical studies, focusing on the modeling of MSW materials and storage sites, and on leaching as the main chemical-physical phenomenon that occurs in the contamination processes in the waste storage. The identification of relevant contamination processes, in addition to the number of dimensions that should be considered in a geochemical model, usually depend upon the geological and hydrological setting of the system [14], which play an essential role in the transport of contaminants, as illustrated in Figure 2.

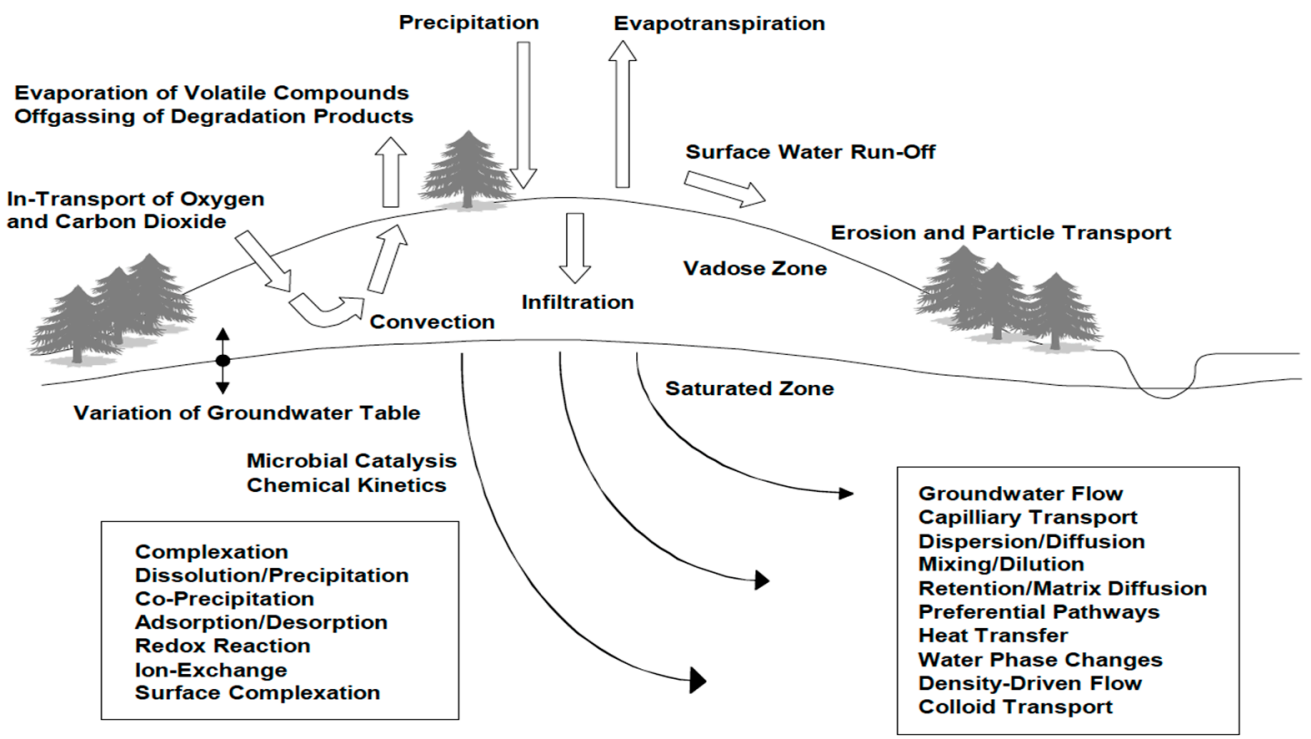

Figure 2. Conceptual diagram, illustrating leaching and reactive transport processes that are of importance in municipal solid waste (MSW) storage sites and that can lead to groundwater contamination problems. Reused from Crawford [14]. 
Groundwater contamination, which progressively reaches aquifers, is often caused by hazardous spills and leakages; however, this review emphasizes the processes associated with landfill leachate and infiltration. Modeling these complex pollutant systems over decades and centuries to predict contaminant behavior, using chemistry and geochemistry mechanisms such as solid-solution partitioning, complexation, sorption, redox reaction, solubility and other processes, is a difficult task. Knowledge of the geology and hydraulic gradient at the site, and installation of monitoring wells are costly and time consuming, making the models that describe these complex processes an important tool for assessment of possible contaminants and their fate [15].

The leaching behavior of major contaminant elements is strongly influenced by $\mathrm{pH}$, solubility and sorption properties, forming major interconnected mechanisms that control the release of pollutants in the leachate. The principal potential mechanism for leaching is the solubility of constituent's species under specific environmental conditions, together with the sorption process onto surface sites within soil organic matter, clay and metal hydroxides. Solubility and sorption are directly related to $\mathrm{pH}$ for several elements. For instance, $\mathrm{Ca}, \mathrm{Mn}, \mathrm{Zn}, \mathrm{Cd}$, and $\mathrm{Pb}$ (i.e., metal species) obey a "cationic leaching pattern", reducing solubility and sorption in less acidic environments due to lower positive surface sites of metal hydroxides [16,17]. Leaching can be analyzed by measuring the leachate concentrations in field samples (point of compliance), and can be experimentally verified by various lab-based measuring methodologies that are categorized into static batch leaching tests (mixture of solid waste and water agitated and filtered), column leaching tests (simulates the flow similar to field conditions), and $\mathrm{pH}$-static leaching test (evaluates solubility/sorption/precipitation under different $\mathrm{pH}$ conditions) [16].

\subsection{Geochemical Modeling Application}

In recent decades, it is notorious the increasing number of software, databases, training and a prominent a variety of applications of geochemical modeling around the world. Geochemical modeling has found applications ranging from (i) leaching behavior of solid, to (ii) the removal of heavy metals from natural waters, to (iii) the long-term durability of building materials, to (iv) geological sequestration of carbon dioxide, among others.

In many research areas, geochemical modeling software (main software and databases mentioned in the reviewed papers are listed in Table S1 in the Supplementary Material) play an important function. In this review, the majority of the papers examined are related to the modeling of mass transfer in groundwater, known as reactive transport modeling, which analyzes solutes carried by water flow through the soil. Transport modeling, via molecular diffusion and hydrodynamic dispersion, is thus combined with reaction modeling [18]. The flow of liquids through the porous media can be mathematically described using transport equations derived from the conservation of mass principle and taking into account hydraulic conductivity, which is related to the permeability of the soil and viscosity of the liquid, while reaction models consider thermodynamic equilibrium calculations to predict the distribution among species and minerals (Figure 3). Landfill leaching is a classic example of contaminant transport through soil media, which is controlled by advection (bulk motion), dispersion (turbulent diffusion with velocity gradients) and sorption in a reaction model.

Related to MSW, the main applications of geochemical modeling have been to: (i) optimize remediation efforts; (ii) identify parameters of importance in groundwater systems; (iii) design effective techniques to retard the release of hazardous materials to groundwater; (iv) bridge the gap between laboratory experiments and field data; and provide long-term environmental assessment of waste applications. 


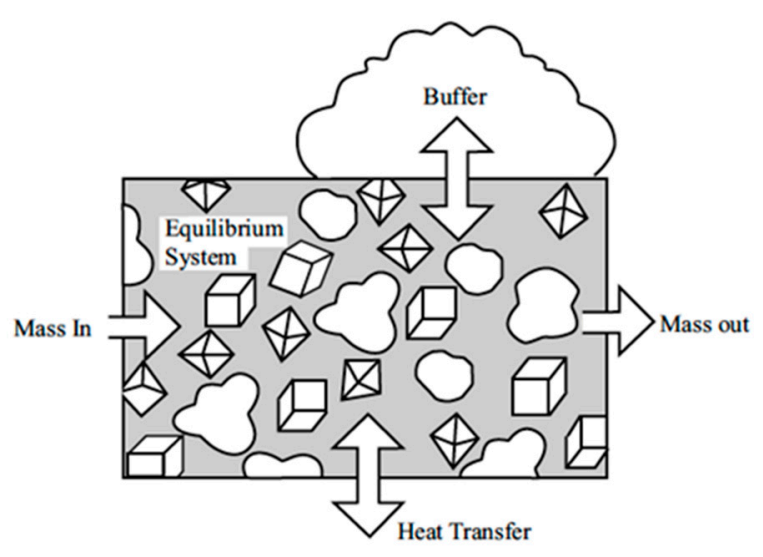

Figure 3. Schematic diagram of a reaction model [18].

\section{Adopted Methodology for Literature Review}

The current study is based on a review of the literature that is composed of articles written in the last two decades retrieved from the Web of Science database. The keywords used for the literature search included "municipal solid waste", "landfill", "leaching" and "geochemical modeling". Further studies were identified through the reference list of selected articles, and Google Scholar was used to find reports or conference proceedings about contaminant processes of MSW.

Several analyses were performed, considering different aspects addressed in the 34 articles studied. First, the types of materials analyzed were surveyed, such as: fly ash, clay, cement, among others. Afterwards, the types of analyses obtained in the laboratories and by the geochemical model were determined, such as: potential pollution index, hazard index, contamination factors, among others [19]. It was also observed which chemical elements were more frequently analyzed, such as: heavy metals, methane, ammonium, $\mathrm{CO}_{2}$, oxides, hydrates, acids, among others. Finally, the most common software used were determined, as well as their main analyses: adsorption capacity, precipitation, diffusion coefficient, $\mathrm{pH}$ calculation, ionic strength, carbon mass variation, among other outputs obtained by the software. In addition, it was assessed which phenomena are addressed by the models, such as: model of chemical speciation of equilibrium, transport simulation, cation exchange, dissolution reaction, surface complexation, among others.

The aim, through the study of the latest research in the area of interest, was to verify which are the main analyses that are being performed with satisfactory results, in addition to detecting which advances should be made and the limitations observed. To facilitate the organization of the collection of this information, an approach similar to the "discourse of the collective subject" (DCS) was used [20], in order to identify the most recurrent analyses or content and verify which provided the most significant data. This method consists of an analysis of content, divided into categories, such as: sample collection, data analysis, problems observed, geochemical modeling application, and main outputs, among other approaches. The interpretation of each response was carried out in order to extract the key expressions and central ideas contained in them, and to frame them in some specific class. The application of this technique has demonstrated its effectiveness in processing and expressing collective opinions, in order to group the main points studied in the articles, as well as their quantification.

\section{Results}

A comprehensive review was developed with 34 articles, summarizing the main geochemical modeling outputs, how experimental samples were collected, the type of data collected, and how experimental and modelled data were compared to validate the results and to assess the ability of the model to predict the release of the contaminants in long-term condition, at different $\mathrm{pH}$ and as a function of many other parameters. Table 1 shows the main data collected from the reviewed articles. 
Table 1. The types of waste treatment processes and waste materials most analyzed in the articles reviewed.

\begin{tabular}{cc}
\hline Characteristic Observed & Articles Analyzed \\
\hline $\begin{array}{c}\text { Articles that deal with MSW incineration residues } \\
\text { (bottom and fly ashes) }\end{array}$ & {$[11,21-30]$} \\
\hline Articles that deal with open dumps & {$[19,31-34]$} \\
\hline Articles that deal with different types of landfills & {$[13,29,35-40]$} \\
\hline Articles that deal with composting & {$[41-44]$} \\
\hline Clay analysis & {$[35,41,45,46]$} \\
\hline Cementitious waste & {$[11,42,44]$} \\
\hline Soil analysis & {$[13]$} \\
\hline Wastewater analysis & {$[39,40]$} \\
\hline Sand analysis & {$[36]$} \\
\hline Brine (High salt concentration by-product) & {$[24]$} \\
\hline Steel Slags (by-product of steel making) & {$[28]$} \\
\hline $\begin{array}{c}\text { Phosphogypsum (by-product of phosphoric acid and } \\
\text { phosphate fertilizers from phosphate rocks) }\end{array}$ & {$[47]$} \\
\hline Biosolids (sewage sludges) & {$[40]$} \\
\hline
\end{tabular}

As studies dedicated to MSW management are limited in number, several relevant articles relating more generally to solid waste management, such as those on industrial waste management, have also been selected for review to complement the discussion. Learnings from such papers can be useful for future implementation of geochemical modeling in MSW management. In terms of industrial waste materials, Table 1 additionally summarizes research involved in collecting experimental data for geochemical modeling to simulate and predict leaching behavior in different types of industrial wastes.

Among the articles studied, it is important to identify which are the main contaminants analyzed and models studied, as well as the software/codes used, in order to examine the trend relative to the studies of geochemical models (Table 2). In this way, it is possible to observe study gaps and analyses that need to be further deepened.

Table 2. Relationship between number of occurrences and the main software, contaminants, analyses and models studied/used in the reviewed articles.

\begin{tabular}{cc}
\hline Software & Number of Occurrences \\
\hline MINTEQA2 & 18 \\
PHREEQC v2 & 10 \\
ORCHESTRA & 7 \\
LeachXS & 3 \\
AQUACHEM & 3 \\
Geochemist's workbench & 2 \\
HYTEC; EQ3/6 & 3 \\
CHESS; PHREECI; Pitzer & 1 \\
\hline Simulation/Model & Number of Occurrences \\
\hline Model of chemical speciation of equilibrium & 25 \\
Sorption and ion exchange & 5 \\
Redox process and re-dissolution & 4 \\
Transport simulation; Surface complexation & 3 \\
Nonideal competitive adsorption-Donnan model; Cation exchange; Mass & 2 \\
distribution simulation; Simulation of a reactive transport model & \\
\hline
\end{tabular}


Table 2. Cont.

\begin{tabular}{|c|c|}
\hline Contaminants Investigated & Number of Occurrences \\
\hline $\mathrm{Cl}, \mathrm{Cu}, \mathrm{Ca}, \mathrm{Pb}$ & 16 \\
\hline $\mathrm{Mg}, \mathrm{Zn}$ & 15 \\
\hline $\mathrm{Cd}, \mathrm{Na}$ & 14 \\
\hline $\mathrm{SO}_{4}{ }^{2-}, \mathrm{Cr}$ & 13 \\
\hline $\mathrm{Ni}, \mathrm{Fe}, \mathrm{K}$ & 12 \\
\hline $\mathrm{Al}$ & 11 \\
\hline Total organic carbon & 10 \\
\hline $\mathrm{Mn}, \mathrm{As}$ & 9 \\
\hline Si & 8 \\
\hline Mo & 7 \\
\hline $\mathrm{Ba}, \mathrm{Sr}$ & 6 \\
\hline $\mathrm{P}, \mathrm{Co}, \mathrm{Sb}$ & 5 \\
\hline $\mathrm{S}, \mathrm{Li}, \mathrm{V}, \mathrm{NH}_{4}^{+}, \mathrm{CO}_{2}$, total inorganic carbon & 4 \\
\hline $\mathrm{Be}, \mathrm{Se}, \mathrm{NO}_{3}{ }^{-}, \mathrm{SO}_{4}{ }^{2-}, \mathrm{PO}_{4}{ }^{3-}, \mathrm{Sn}, \mathrm{Ti}, \mathrm{B}, \mathrm{Fe}_{2} \mathrm{O}_{3}$ & 3 \\
\hline $\mathrm{F}, \mathrm{Hg}$ & 2 \\
\hline $\mathrm{N}, \mathrm{HCO}_{3}{ }^{-}, \mathrm{CN}^{-}, \mathrm{HNO}_{3}$, humic and fulvic acids, $\mathrm{CH}_{4}, \mathrm{CO}_{3}, \mathrm{Rb}, \mathrm{Br}, \mathrm{Bi}$ & 1 \\
\hline Most Frequent Analyses & Number of Occurrences \\
\hline Precipitation, mineral saturation levels, calculating the $\mathrm{pH}$ & 10 \\
\hline Solubility & 7 \\
\hline Adsorption capacity & 4 \\
\hline Organic carbon content & 3 \\
\hline Variation of dissolved carbon mass, evaluation of $\mathrm{CO}_{2}$ sequestration potential & 2 \\
\hline $\begin{array}{l}\text { Isotherms of sorption; ionic strength determination; proton-buffering and cation } \\
\text { exchange capacity; apparent diffusion coefficients; distribution coefficient }\end{array}$ & 1 \\
\hline Studies that emphasize some limitations of geochemical modeling & 2 \\
\hline
\end{tabular}

Source: Cited references.

\section{Discussion}

The application of appropriate geochemical models in solid waste management has attracted the attention of researchers and practitioners in the area of decision support systems, because through the use of the modeling tools in this area one can represent a real world situation, study its behavior, and make decisions based on the conclusions drawn. Geochemical modeling has been developing continuously, since its introduction in the 1970s, in relation to the main environmental problems it tackles, so the present review aimed to highlight these advances, challenges and limitations. The heterogeneity of solid wastes and the parameterization of the models are significant challenges observed over the years. The use of geochemical modeling, in most cases, is linked to the description of the interaction between water, minerals and gases present in an aqueous system. Therefore, in this review, it was observed that geochemical models are used as essential tools to predict the behavior of several contaminants of interest in the interaction between groundwater, landfill leachate and geological setting.

\subsection{The Types of Waste Treatment Processes and Waste Materials}

The analysis of incineration ashes represented approximately 40\% of the reviewed articles [11,21-29]. In various regions around the world, particularly those with strict landfilling regulations and/or lack of physical space for landfill expansion, one of the most commonly used solutions for MSW management is incineration, namely: burning of solid residues, at very high temperatures, until their transformation into ashes, with the objective of reducing the mass and volume of these residues. Due to this scenario and the large production of pollutants, a greater number of researches are observed in this type of solid waste treatment.

In the management MSW storage sites, soil analysis is important, and thus it is where most research occurs with the aim to prevent soil contamination. Knowing the behavior of contaminants in the subsurface environment is important for predicting environmental accidents and evaluating possible solutions. Contamination processes occur slowly and often without immediate tragic consequences, 
but in the long-term can cause serious and possibly irreversible effects, being the environment with the highest probability of accidents $[47,48]$. Several authors have used modeling to reproduce the mobility of chemical elements in the subsurface. Promising results were observed in the analysis of contaminants in clay media, evolution of analysis of porous media. On the other hand, few studies were observed in hydrogeochemical environments.

\subsection{Features of Geochemical Modeling Software}

Although it does not replace laboratory experiments, modeling and simulation by software have special value as a predictive tool, and it can be used as a bridge for more elaborate experimentation in laboratories, field observations and the behavior of geochemical systems. The association of both techniques, modeling and standard leaching testing, is a valuable tool to understand the behavior of waste, and to better determine mineralogical characterization. However, the modeling software may have some limitations, among them the internal consistency of the database data, limitation of some reactions, and the need to include new models capabilities. Therefore, it is interesting to check which programs are most used according to their application.

Bisone et al. [49], Zhang et al. [50] and Korfali et al. [32] used PHREEQC, one of the most widely used software to predict soil contamination. PHREEQC is a relatively versatile code that can model many different types of fixed temperature reactions; however, its database is limited, particularly for trace elements, and it is also a difficult code for beginners. MINTEQA2 is another commonly employed software for this line of research [19,34,42], being considered user-friendly, but with some calculation limitations that restrict the complexity of the model.

The ORCHESTRA model was another occasionally used software in certain situations [21,22]. This software has been used for a wide range of applications including aqueous speciation, precipitation, different forms of surface complexation, ion exchange, diffusion, convection, solid solutions, adsorption, among others. The speciation of elements is governed by several interrelated processes, which include organic and/or inorganic complexation, oxidation/reduction reactions, precipitation/dissolution and adsorption/desorption. Analysis in aqueous media has also been evaluated, less commonly, using the AQUACHEM software that interfaces with PHREEQC, using its specific speciation equation. Other geochemical modeling codes used for these types of analysis have been: HYTEC, EQ3/6, LeachXS, WHAM VI, OLI, and The Geochemist's Workbench [11,24,28,51].

\subsection{Contaminants Investigated}

The understanding of the type of destination of solid wastes, whether it be dumps, controlled landfills or non-regulated landfills, is important to understand which types of analyses are relevant, and which mechanisms are preponderant, analyzing the soil or the water. In the papers herein reviewed, the main contaminants analyzed were heavy metals, sulfates and dissolved organic carbon. Some of these substances can cause risks to human health and ecological receptors. Thus, understanding the behavior of these substances in subsurface is fundamental for the establishment of environmental intervention measures aimed at the recovery of areas with solid waste deposits.

Although important, few studies were observed regarding the gases produced in solid waste treatment. The inadequate disposal of waste releases gases into the environment, polluting the atmosphere, contributing to the greenhouse effect, and causing discomfort to the population, either by the unpleasant odor or by causing respiratory diseases. The analysis of volatile organic carbon gases could be more frequent, but in the most modern landfills, where the disposal of hazardous waste is prohibited, the concentrations of volatile organic compounds have been extremely low, justifying the lower regularity of these analyses. Other substances analyzed were methane and carbon dioxide from the decomposition of organic matter $[37,45]$. Methane, is one of the main gases originating from the anaerobic decomposition of the biodegradable components of organic waste in MSW, being quite dangerous. Some articles have verified $\mathrm{CO}_{2}$ concentrations using geochemical modeling $[33,38,43]$. 
The gas tends to move to the bottom of the landfill, and as a result the carbon dioxide concentrations in the lower parts of the landfill may be high for years, and it is essential to monitor and study its behavior.

In general, there is little information on the composition of organic matter dissolved in landfill slurry. However, some investigations focus on organic carbon dissolved in landfill leachate $[33,45]$. In the acid phase the slurry has more than $95 \%$ of the dissolved organic matter content of volatile fatty acids and only $1.3 \%$ of dissolved organic carbon with high molecular weight [52]. Cations and anions such as: calcium, magnesium, sodium, potassium, $\mathrm{NH}_{4}{ }^{+}$, iron, manganese, $\mathrm{HCO}_{3}{ }^{-}$, chlorides and sulfates were the main inorganic components studied, so that the concentration of these inorganic components in the slurry depends on the landfill stabilization processes [22,24,36]. Regarding heavy metals, cadmium, aluminum, arsenic, copper, lead, nickel, zinc, chromium, molybdenum, barium, vanadium, titanium, mercury, among others, were highlighted as shown in Table 2. In general, the concentrations of heavy metals in slurries from different landfills present great variations, so specific studies are necessary to verify their behavior in each medium.

In some situations, limitations were observed in the modeling of some important chemical elements. For example, Tiberg et al. [34] found problems in modeling lead, but Martens et al. [44] reported good reproduction results for lead, but unsatisfactory for magnesium. This may be attributed to various factors including the parameterization of $\mathrm{Pb}$ binding to humic substances and oxides, the exclusion of $\mathrm{MnO}$ from some assemblage models, or significant non-additive effects on binding [53]. The studies of these toxic elements are essential, as they cause harmful problems to the human body. For example, the interaction of lead has an accumulative effect, affecting all organs and systems of the body. Thus, significant advances in geochemical modeling have been observed, so that important types of analysis can be obtained, in addition to similar results compared with laboratory tests.

\subsection{Analyses and Models Studied}

Several mechanisms were observed in the reported studies, varying according to the medium to be studied and the type of leachate. The understanding of the performance of these processes is fundamental in order to indicate adequate solutions for environmental intervention in areas contaminated by solid waste landfills. Modeling has been used mainly to define the species that most influence the spatial behavior of the waste. In addition, the most frequent analyses were chemical speciation of the elements, precipitation, determination of solubility, saturation levels, among others. In these analyses, deeper dissolution reactions, sorption mechanisms, oxidation and reduction reactions, surface complexation, mass distribution, ionic strength distribution and transport simulation were common.

Based on the data obtained by geochemical modeling it is possible to understand: the fractions of the nature of potentially toxic elements; the potential pollution index (PI) and hazard index $(\mathrm{HI})$; the influence of organic matter on the leaching of elements; how to predict drainage water treatment requirements before discharge (simulations can draw guidelines); the health risk of metals; the enrichment factor, geographical accumulation index, contamination factors and pollutant load index; the risk assessment code and individual/global contamination factor and global contamination factor [19].

The use of equilibrium geochemical models to calculate the solubilities and aqueous speciation of contaminants is well established in the field of geochemical modeling. It is worth noting that surface complexation is a more robust analysis, but not yet widely used, but were observed in some studies $[40,44]$. The challenge in applying the surface complexation concept in the environment is to simplify the adsorption model, such that predicted adsorption is still calculated with mass laws that are coupled with aqueous speciation [54]. In addition, the theory of ion exchange may well explain the sorption of the main cationic species in the clay fraction of a soil or sediment $[45,46]$.

The surface complexing models also allow a quantitative exploration of the effects of surface speciation on the reactivity of the solute with the surface [55]. However, it should be recognized that there is often little reliable data to quantify the relevant model parameters. Nevertheless, in recent 
years, the availability of thermodynamic data for surface reactions and confirmation of the structure of adsorbed surface complexes has increased considerably. The literature shows that the use of surface complexation models to describe the transport of heavy metals in groundwater has been quite limited, but improved over the last decade, with valuable results [21,31,40,56].

From a theoretical point of view, the NICA-Donnan equation is well studied, with well consolidated studies. On the other hand, from the chemical-physical point of view it may be possible to reassess the Donnan model, or at least the way the Donnan volume is calculated, especially in the case of fulvic acids, and in situations where the ionic strength of the medium can be defined by divalent cations, such as magnesium [44]. Recently, this model has been adjusted in order to obtain the parameters of the NICA-Donnan model from experimental data, using an ORCHESTRA platform coupling. This combination is very versatile, and the models can be easily implemented and modified on the platform. The NICA-Donnan model is also implemented in the chemical speciation code of Visual MINTEQ. It was observed evolution of analysis of some reactions, such as cation exchange, NICA-DONNAN equation, and a greater depth of thermodynamic data, bringing greater robustness to the software used.

Reactive transport codes for unsaturated zones have been observed as promising tools to uncover the complex interaction between soil physics and biogeochemical processes for a number of problems, including the impact of natural processes and anthropogenic activities on soil evolution $[45,46,57]$. There is complexity in the analysis of element transport in a porous medium, also because the flow in a variably saturated medium affects many of the variables ( $\mathrm{pH}$, concentration) that influence the geochemical equilibrium. However, multi-surface geochemical modeling approach for landfill maintenance reduction or closure showed promising results when considering main sorption mechanisms [13]. Studies of many contaminated field systems have demonstrated that adsorption-desorption is the most significant geochemical process affecting the transport of inorganic contaminants at specific field sites [58].

Another mechanism studied in some research was the distribution coefficient $\mathrm{Kd}$, though care should be taken in its application. This coefficient is important in describing linear equilibrium adsorption models based on a component, in which the distribution of the solute between the liquid and solid phases is verified. However, this analysis can lead to completely different concentration patterns from those predicted using a cation exchange model that considers ionic competition or the surface complexation model [57]. This is due to the inability of the Kd model to consider spatial and temporal variations in soil water chemistry and soil water content itself. This is one of the reasons why research has intensified on the improvement of models that integrate all relevant processes in the speciation and transport of chemical species in the soil. However, for more simplistic conditions, under more generic conditions, in the analysis of leachate contamination, the results have been satisfactory [35]. In addition, there have been restrictions of the distribution coefficient studies to simpler analyses, scarcity of more studies in the analysis of surface complexation, and challenges in the analysis of concentrations of certain elements. Therefore, it is remarkable that geochemical modeling is an important tool, but it is necessary to understand its limitations.

\subsection{Geochemical Modeling Outlook for Solid Waste Management}

It is important to verify if the equilibrium constants for the important reactions in the thermodynamic data set are accurate enough, if the thermodynamic data set contains the species and minerals likely to be important in the study. In addition, consider whether the chemical analysis used is precise enough to support the modeling study in order to minimize errors in geochemical modeling. It is interesting that the modeler should begin work by integrating experimental results and field observations into the study. Having successfully explained the experimental or field data, the modeler can extrapolate to make predictions with greater confidence.

In this context, some actions are necessary in order to eliminate or reduce the problems arising from the analysis of geochemical models. These include: standardized characterization of MSW 
between countries for better understanding and comparison, allowing the use of previous surveys; improved geological characterization on site, for more accurate predictions of the leaching behavior of possible contaminants in groundwater; mounting of different types of models and databases to include more mechanisms and data from each proprietary approach; more research to avoid underestimation of contaminants in altered conditions and regulatory processes in the environment; and defining an overall criterion of contaminant concentrations in landfill leachate during an assessment period (e.g., 600 years in the long term) to avoid health problems related to groundwater contamination.

\section{Conclusions}

Based on the literature review conducted and presented in this review, it is possible to conclude that the studies demonstrated that geochemical modeling is a valuable tool for the prediction of leaching of contaminants in natural environments and laboratory experiments, when using the right models and methods. The geochemical models are valuable to complement laboratory studies based on batch and column tests that attempt to reproduce flow conditions in the field to predict the behavior and mobility of contaminants in the subsurface. Geochemical modeling has proven to be a useful tool when planning, implementing and adapting solid waste management systems. However, it is still not widely explored in new sites, especially in developing countries. Few studies related to transport modeling or under hydrological conditions were observed, with most studies being related to metal speciation based on geochemical equilibrium models.

Specifically, in summary: the most used analyses were in relation to precipitation, saturation level and pH calculation; the most applied software were MINTEQA2, PHREEQC v2 and ORCHESTRA; most studies are related to incineration residues; and limitations were observed in the analyses of lead and magnesium. Methodologic limitations that can possibly have impacted this work include: (1) the sample size, given that geochemical modeling applied to MSW is a specific field of the study, 34 articles qualitatively analyzed could be not enough; and (2) the lack of studies exclusively dedicated to MSW management.

The information provided is meant to be useful for understanding leaching mechanisms of contaminants from landfills and open dumps, and for specialists when planning, implementing and/or adapting solid waste management systems. As next steps, we suggest that more research be done to comprehend the threats of municipal solid waste disposal to the environment and human health with the aid of geochemical modeling, and to assess the potential (for future projects) or effectiveness (for ongoing projects) of improved MSW management practices. Given the multidisciplinarity of solid waste management studies (involving environmental and earth sciences, engineering, public health, social behavior, politics, among others), it is critical that MSW projects have multidisciplinary teams, and large enough size to tackle all relevant aspects. This calls on governments and funding agencies to dedicate more resources to such a project, in such a way that experts on geochemical modeling can be a part of it. In summary, the more non-experts on geochemical modeling learn about its capabilities and usefulness, and the more experts in geochemical modeling work closely with those non-experts, the more progress will be made in improving the sustainability of MSW management systems.

Supplementary Materials: The following are available online at http://www.mdpi.com/2075-163X/10/10/846/s1, Table S1: Main software and databases related to Geochemical Modelling mentioned in the review.

Author Contributions: Conceptualization, F.A. and R.M.S.; methodology, F.A. and R.M.S; validation, R.M.S.; investigation, F.A., H.F., E.N. and R.M.S.; writing — original draft preparation, F.A.; writing—review and editing, H.F., E.N. and R.M.S.; visualization, F.A. and H.F.; supervision, R.M.S.; project administration, R.M.S. All authors have read and agreed to the published version of the manuscript.

Funding: This research received no external funding.

Conflicts of Interest: The authors declare no conflict of interest. 


\section{References}

1. World Bank. Trends in Solid Waste Management. A Global Snapshot of Solid Waste Management to 2050. 2016. Available online: http://datatopics.worldbank.org/what-a-waste/trends_in_solid_waste_management.html (accessed on 15 October 2019).

2. Liu, X.; Li, X.-M.; Yang, Q.; Yue, X.; Shen, T.-T.; Zheng, W.; Luo, K.; Sun, Y.-H.; Zeng, G.-M. Landfill leachate pretreatment by coagulation-flocculation process using iron-based coagulants: Optimization by response surface methodology. Chem. Eng. J. 2012, 200-202, 39-51. [CrossRef]

3. Patil, C.; Narayanakar, S.; Virupakshi, A. Assessment of groundwater quality around solid waste landfill area-a case study. Int. J. Innov. Res. Sci. Eng. Technol. 2013, 2, 3131-3136.

4. Vaccari, M.; Vinti, G.; Tunder, T. An analysis of the risk posed by leachate from dumpsites in developing countries. Environments 2018, 5, 99. [CrossRef]

5. Nwagbie, N.M.; Wirlen, Y.L.; Yinda, G.S.; Vander Zaag, A.C. Quantifying greenhouse gas emissions from municipal solid waste dumpsites in Cameroon. Waste Manag. 2019, 87, 947-953. [CrossRef]

6. Ojuri, O.O.; Ayodele, F.O.; Oluwatuyi, O.E. Risk assessment and rehabilitation potential of a millennium city dumpsite in Sub-Saharan Africa. Waste Manag. 2018, 76, 621-628. [CrossRef] [PubMed]

7. Achillas, C.; Moussiopoulos, N.; Karagiannidis, A.; Banias, G.; Perkoulidis, G. The use of multi-criteria decision analysis to tackle waste management problems: A literature review. Waste Manag. Res. 2013, 31, 115-129. [CrossRef]

8. Soltani, A.; Hewage, K.; Reza, B.; Sadiq, R. Multiple stakeholders in multi-criteria decision-making in the context of Municipal Solid Waste Management: A review. Waste Manag. 2015, 35, 318-328. [CrossRef]

9. Themelis, N.J.; Ulloa, P.A. Methane generation in landfills. Renew. Energy 2007, 32, 1243-1257. [CrossRef]

10. Abdel-Shafy, H.I.; Mansour, M.S.M. Solid waste issue: Sources, composition, disposal, recycling, and valorization. Egypt. J. Pet. 2018, 27, 1275-1290. [CrossRef]

11. Du, B.; Li, J.; Fang, W.; Liu, Y.; Yu, S.; Li, Y.; Liu, J. Characterization of naturally aged cement-solidified MSWI fly ash. Waste Manag. 2018, 80, 101-111. [CrossRef]

12. Joseph, A.M.; Snellings, R.; Van den Heede, P.; Matthys, S.; De Belie, N. The Use of Municipal Solid Waste Incineration Ash in Various Building Materials: A Belgian Point of View. Materials 2018, 11, 141. [CrossRef] [PubMed]

13. Dijkstra, J.J.; Zomeren, A.; Brand, E.; Comans, N.J.R. Site-specific aftercare completion criteria for sustainable landfilling in the Netherlands: Geochemical modeling and sensitivity analysis. Waste Manag. 2018, 75, 407-414. [CrossRef] [PubMed]

14. Crawford, J. Geochemical Modeling-A Review of Current Capabilities and Future Directions; Department of Chemical Engineering and Technology, Division of Chemical Engineering; Royal Institute of Technology (KTH): Stockholm, Sweden, 1999; ISRN SNV-R-262-SE.

15. Schnoor, J.L. Groundwater contaminants. In Environmental Modeling: Fate and Transport of Pollutants in Water, Air, and Soil; Wiley: New York, NY, USA, 1996; p. 682, Chapter 9.

16. Luo, H.; Cheng, Y.; He, D.; Yang, E. Review of leaching behavior of municipal solid waste incineration (MSWI) ash. Sci. Total Environ. 2019, 668, 90-103. [CrossRef] [PubMed]

17. Gronenberg, J.E.; Dijkstra, J.J.; Bonten, L.T.; de Vries, W.; Comans, R.N. Evaluation of the performance and limitations of empirical partition-relations and process based multisurface models to predict trace element solubility in soils. Environ. Pollut. 2012, 166, 98-107. [CrossRef]

18. Bethke, C. Geochemical and Biogeochemical Reaction Modeling; Cambridge University Press: Cambridge, UK, 2007. [CrossRef]

19. Sahariah, B.; Goswami, L.; Farooqui, I.U.; Raul, P.; Bhattacharyya, P.; Bhattacharya, S. Solubility, hydrogeochemical impact, and health assessment of toxic metals in municipal wastes of two differently populated cities. J. Geochem. Explor. 2015, 157, 100-109. [CrossRef]

20. Lefevre, F.; Lefevre, A.C. Discourse of the collective subject: Social representations and communication interventions. Texto Contexto-Enferm. 2014, 23, 502-507. [CrossRef]

21. Maresca, A.; Hyks, J.; Astrup, T.F. Long-term leaching of nutrients and contaminants from wood combustion ashes. Waste Manag. 2018, 74, 373-383. [CrossRef]

22. Hyks, J.; Nesterov, I.; Mogensen, E.; Jensen, P.A.; Astrup, T. Leaching from waste incineration bottom ashes treated in a rotary kiln. Waste Manag. Res. 2011, 29, 995-1007. [CrossRef] 
23. Mahedi, M.; Cetin, B.; Dayioglu, A.Y. Leaching behavior of aluminum, copper, iron and zinc from cement activated fly ash and slag stabilized soils. Waste Manag. 2019, 95, 334-355. [CrossRef]

24. Grace, M.N.; Leslie, P.F.; Frédéric, D.J. Geochemical modeling of brine remediation using accelerated carbonation of fly ash. Desalination Water Treat. 2015, 57, 4853-4863. [CrossRef]

25. Van Zomeren, A.; Comans, R.N.J. Contribution of Natural Organic Matter to Copper Leaching from Municipal Solid Waste Incinerator Bottom Ash. Environ. Sci. Technol. 2004, 38, 3927-3932. [CrossRef] [PubMed]

26. Meima, J.A.; Comans, R.N.J. Geochemical modeling of weathering reactions in municipal solid waste incinerator bottom ash. Environ. Sci. Technol. 1997, 31, 1269-1276. [CrossRef]

27. Astrup, T.; Dijkstra, J.J.; Comans RN, J.; Van Der Sloot, H.A.; Christensen, T.H. Geochemical modeling of leaching from MSWI air-pollution-control residues. Environ. Sci. Technol. 2006, 40, 3551-3557. [CrossRef]

28. Windt, L.; Chaurand, P.; Rose, J. Kinetics of steel slag leaching: Batch tests and modeling. Waste Manag. 2011, 31, 225-235. [CrossRef]

29. Travar, I.; Andreas, L.; Kumpiene, J.; Lagerkvist, A. Development of drainage water quality from a landfill cover built with secondary construction materials. Waste Manag. 2015, 35, 148-158. [CrossRef]

30. Dijkstra, J.J.; Meeussen, J.C.L.; Van der Sloot, H.A.; Comans, R.N.J. A consistent geochemical modeling approach for the leaching and reactive transport of major and trace elements in MSWI bottom ash. Applied Geochemistry 2008, 23, 1544-1562. [CrossRef]

31. Dijkstra, J.J.; Meeussen, J.C.L.; Comans, R.N.J. Leaching of heavy metals from contaminated soils: An experimental and modeling study. Environ. Sci. Technol. 2004, 38, 4390-4395. [CrossRef]

32. Korfali, S.I.; Karaki, H. Speciation of Metals in Soils and Water: Risk Assessment. Environ. Process. 2018, 5, 101-125. [CrossRef]

33. Payán, M.; Verbinnen, B.; Galan, B.; Coz, A.; Vandecasteele, C.; Viguri, J.R. Potential influence of $\mathrm{CO}_{2}$ release from a carbon capture storage site on the release of trace metals from marine sediment. Environ. Pollut. 2012, 162, 29-39. [CrossRef]

34. Tiberg, C.; Bendz, D.; Theorin, G.; Kleja, D.B. Evaluating solubility of Zn, Pb, Cu and Cd in pyrite cinder using leaching tests and geochemical modeling. Appl. Geochem. 2017, 85, 106-117. [CrossRef]

35. Pivato, A.; Raga, R. Tests for the evaluation of ammonium attenuation in MSW landfill leachate by adsorption into bentonite in a landfill liner. Waste Manag. 2006, 26, 123-132. [CrossRef] [PubMed]

36. Islam, J.; Singhal, N. A laboratory study of landfill-leachate transport in soils. Water Res. 2004, 38, $2035-2042$. [CrossRef]

37. Van der Sloot, H.A.; Kosson, D.S.; van Zomeren, A. Leaching, geochemical modeling and field verification of a municipal solid waste and a predominantly non-degradable waste landfill. Waste Manag. 2017, 63, 74-95. [CrossRef] [PubMed]

38. Noack, C.W.; Dzombak, D.A.; Nakles, D.V.; Hawthorne, S.B.; Heebink, L.V.; Dando, N.; Gershenzon, M.; Ghosh, R.S. Comparison of alkaline industrial wastes for aqueous mineral carbon sequestration through a parallel reactivity study. Waste Manag. 2014, 34, 1815-1822. [CrossRef]

39. Magu, M.M.; Govender, P.P.; Ngila, J.C. Geochemical modeling and speciation studies of metal pollutants present in selected water systems in South Africa. Phys. Chem. Earth Parts ABC 2015, 92, 44-51. [CrossRef]

40. Apul, D.S.; Diaz, E.M.; Gustafsson, J.P.; Hundal, L.S. Geochemical Modeling of Trace Element Release from Biosolids. Environ. Eng. Sci. 2010, 27, 743-755. [CrossRef]

41. Cuevas, J.; Leguey, S.; Garralón, A.; Rodríguez Rastrero, M.; Procopio, J.R.; Sevilla, M.T.; Sánchez Jiménez, N.; Rodríguez Abad, R.; Garrido, A. Behavior of kaolinite and illite-based clays as landfill barriers. Appl. Clay Sci. 2009, 42, 497-509. [CrossRef]

42. Halim, C.E.; Short, S.A.; Scott, J.A.; Amal, R.; Low, G. Modeling the leaching of Pb, Cd, As, and Cr from cementitious waste using PHREEQC. J. Hazard. Mater. 2005, 125, 45-61. [CrossRef]

43. Ghacham, A.B.; Cecchi, E.; Pasquier, L.; Blais, J.; Mercier, G. $\mathrm{CO}_{2}$ sequestration using waste concrete and anorthosite tailings by direct mineral carbonation in gas-solid-liquid and gas-solid routes. J. Environ. Manag. 2015, 163, 70-77. [CrossRef] [PubMed]

44. Martens, E.; Jacques, D.; Van Gerven, T.; Wang, L.; Mallants, D. Geochemical modeling of leaching of Ca, Mg, $\mathrm{Al}$, and $\mathrm{Pb}$ from cementitious waste forms. Cem. Concr. Res. 2010, 40, 1298-1305. [CrossRef]

45. Breukelen, B.M.; Griffioen, J. Biogeochemical processes at the fringe of a landfill leachate pollution plume: Potential for dissolved organic carbon, $\mathrm{Fe}(\mathrm{II}), \mathrm{Mn}(\mathrm{II}), \mathrm{NH}_{4}$, and $\mathrm{CH}_{4}$ oxidation. J. Contam. Hydrol. 2004, 73, 181-205. [CrossRef] 
46. Cuevas, J.; Ruiz, A.I.; Soto, I.S.; Sevilla, T.; Procopio, J.R.; Silva, P.; Gismera, J.M.; Regadío, M.; Jiménez, N.S.; Rastrero, M.R.; et al. The performance of natural clay as a barrier to the diffusion of municipal solid waste landfill leachates. J. Environ. Manag. 2012, 95, S175-S181. [CrossRef] [PubMed]

47. Pivato, A. An overview of the fundamentals of risk assessment applied to the aftercare landfill impact. In Proceedings of the 9th International Landfill Symposium, Cagliari, Italy, 6-10 October 2003.

48. Yong, R.N.; Mohamed, A.M.O.; Warkentin, B.P. Principles of Contaminant Transport in Soils; Elsevier Science: Amsterdam, The Netherlands, 1992; p. 327.

49. Bisone, S.; Gautier, M.; Chatain, V.; Blanc, D. Spatial distribution and leaching behavior of pollutants from phosphogypsum stocked in a gypstack: Geochemical characterization and modeling. J. Environ. Manag. 2017, 193, 567-575. [CrossRef]

50. Zhang, X.; Li, J.; Wei, D.; Li, B.; Ma, Y. Predicting soluble nickel in soils using soil properties and total nickel. PLoS ONE 2015, 10, e0133920. [CrossRef] [PubMed]

51. Zhang, Y.; Chen, J.; Wang, L.; Zhao, Y.; Ou, P.; Shi, W. Establishing a health risk assessment for metal speciation in the soil-A case study in an industrial area in China. Ecotoxicol. Environ. Saf. 2018, 166, $488-497$. [CrossRef] [PubMed]

52. Harmsen, J. Identification of organic compounds in leachate from a waste tip. Water Res. 1983, 17, $699-705$. [CrossRef]

53. Gronenberg, J.E.; Lofts, S. The use of assemblage models to describe trace element partitioning, speciation, and fate: A review. Environ. Toxicol. Chem. 2014, 33, 2181-2196. [CrossRef] [PubMed]

54. Goldberg, S.; Criscenti, L.J.; Turner, D.R.; Davis, J.A.; Cantrell, K.J. Adsorption-desorption processes in subsurface reactive transport modeling. Vadose Zone J. 2007, 6, 407-435. [CrossRef]

55. Goldberg, S. Application of surface complexation models to anion adsorption by natural materials. Environ. Toxicol. Chem. 2014, 33, 2172-2180. [CrossRef]

56. Caruso, B.S.; Cox, T.J.; Runkel, R.L.; Velleux, M.L.; Bencala, K.E.; Nordstrom, D.K.; Smith, K.S. Metals fate and transport modeling in streams and watersheds: State of the science and USEPA workshop review. Hydrol. Process. 2008, 22, 4011-4021. [CrossRef]

57. Jacques, D.; Simunek, J.; Mallants, D.; van Genuchten, M. The Modeling Coupled Hydrologic and Chemical Processes: Long-Term Uranium Transport following Phosphorus Fertilization. Vadose Zone J. 2008, 7, 698-711. [CrossRef]

58. Kent, D.B.; RHAbrams, J.A.; Davis, J.A.; Coston, D.R.; LeBlanc, D.R. Modeling the influence of variable $\mathrm{pH}$ on the transport of zinc in a contaminated aquifer using semiempirical surface complexation models. Water Resour. Res. 2000, 36, 3411-3425. [CrossRef] 